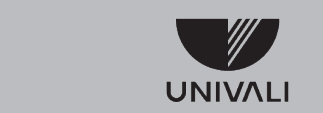

UNIVERSIDADE DO VALE DO ITAJAí

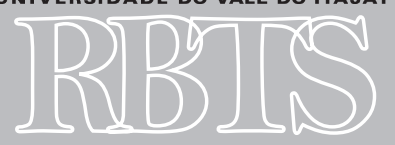

Revista Brasileira de Tecnologias Sociais
* Professora de Ciência Política na Universidade Federal do Maranhão, coordenadora do Observatório de Políticas Públicas e Lutas Sociais e do Grupo de Estudos de Política, Lutas Sociais e Ideologias.

\section{A ATUAL CRISE CAPITALISTA E AS POLÍTICAS PÚBLICAS: DOIS PASSOS ATRÁS}
THE CURRENT CAPITALIST CRISIS AND PUBLIC POLICIES: TWO STEPS BACKWARDS

\author{
Joana A. Coutinho*
}

RESUMO: Este texto busca refletir a atual fase do capitalismo e os impactos para a implementação de políticas públicas. Neste contexto, vimos um retrocesso de garantias de políticas com caráter universal que se focaliza. Buscamos refletir as contradições do Estado capitalista na realização dessa promessa e os conflitos entre as classes sociais, levando-se em consideração as formações sociais no interior do capitalismo globalizado.

PALAVRAS-CHAVES: imperialismo, Estado capitalista; políticas públicas.

ABSTRACT: This text reflects on the current phase of capitalism and the impacts for the implementation of public policies. In this context, we have seen a backward step in the universal policy guarantees that focus. We reflect, here, on the contradictions of the capitalist state in fulfilling this promise, and the conflicts between social classes, taking into account the social formations within globalized capitalism.

KEYWORDS: imperialism, capitalist state; public policy. 
UNIVALI

UNIVERSIDADE DO VALE DO ITAJAÍ

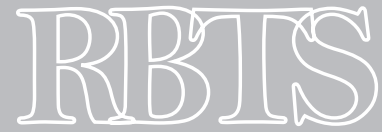

Revista Brasileira de Tecnologias Sociais 


\section{INTRODUÇÃO}

É impossível discutirmos os desafios contemporâneos para as políticas públicas neste momento crucial de um neoliberalismo mais encrudelecido que estamos vivendo. Torna-se necessário três questões, no nosso entendimento, centrais: 1) o Estado Capitalista e sua natureza de classe; 2) o Neoliberalismo e as contrarreformas do Estado capitalista. Para tanto, comecemos com o conceito de Estado e classe.

As políticas públicas não podem ser compreendidas como uma simples "vontade política" do governante, e sim como uma correlação de forças no interior do Estado. Neste sentido, é importante um pequeno resgate do conceito de Estado capitalista. Este Estado só pode ser entendido como um Estado de classe que apresenta o fato da "dominação política estar constantemente ausente das instituições" (POULANTZAS, 1977, p.119). A legitimidade deste Estado está baseada no "conjunto dos indivíduos-cidadãos formalmente livres e iguais, na soberania popular e na responsabilidade laica do Estado para com o povo" (POULANTZAS, 1977, p.119). Neste sentido, o Estado capitalista moderno apresenta-se como encarnando o interesse geral de toda a sociedade. Há uma individualização dos agentes da produção (proletários e capitalistas):

[...] conjunto destes indivíduos-agentes constituiria a sociedade civil, quer dizer, de algum modo o econômico nas relações sociais. A separação entre a sociedade civil e o Estado indicaria assim o papel de uma superestrutura propriamente política com relação a esses indivíduos econômicos, sujeitos da sociedade mercantil e concorrencial. (POULANTZAS, 1977, p.120).

Essa leitura atomizada da sociedade civil impossibilita a "compreensão da relação do Estado com a luta de classes". Com efeito,

[…] os agentes a produção concebidos originariamente como indivíduossujeitos e não como suportes de estruturas, é impossível constituir a partir deles as classes sociais; sendo, por outro lado, o Estado relacionado originariamente com estes indivíduos-agentes econômicos, é impossível relacioná-lo com as classes sociais e a luta de classe; b) Conduz a mascarar uma série de problemas reais postos pelo Estado capitalista, ocultando-o sob a problemática ideológica da separação entre sociedade civil e Estado. (POULANTZAS, 1977, p.121).

Saes (1998) aponta para o efeito neutralizador que provém da esfera do Estado. Segundo o autor, só o Estado burguês torna possível a reprodução das relações de produção capitalistas. O Estado burguês

... cria as condições ideológicas necessárias à reprodução das relações de produção capitalistas. E o faz na medida em que desempenha uma dupla função: a) Individualiza os agentes da produção mediante a sua conversão em pessoas jurídicas: isto é sujeitos individuais aos quais se atribuem direitos e uma vontade subjetiva. Essa individualização confere à troca desigual entre o uso da força de trabalho e o salário a forma de uma tomada de vontade realizado por iguais: isto é, um contrato de compra e venda da força de trabalho (...) b) Neutraliza, no produtor direto, a tendência à ação coletiva, decorrente do caráter privado assumido pelos trabalhos nesse processo. Se a primeira função produz efeitos 
tanto sobre o produtor direto como sobre o proprietário dos meios de produção, esta segunda função produz fundamentalmente efeitos sobre o produtor direto. (SAES, 1998, p. 29).

É a ideia do povo-nação (uma construção ideológica), portanto, que cria a unidade dos membros das classes antagônicas e desempenha a função de neutralizar a organização de classes dos trabalhadores, conservando estes últimos num "estado de massas" e "impedindo a sua constituição em classe social” (SAES, 1998, p. 31).

Claus Offe (1984) reflete como a chamada política social é fruto do processo de industrialização e este, por sua vez, é "acompanhado de processos de desorganização e mobilização da força de trabalho” (OFFE, 1984, p. 15). Offe apresenta dois argumentos para justificar que a socialização, por meio do trabalho assalariado, fosse organizada e sancionada pelo Estado. $\mathrm{O}$ primeiro é que as formas encontradas na fase pré-industrial baseadas em subsistemas, como a família, a caridade, a igreja, perderam eficiência com o desenvolvimento industrial. O segundo argumento consiste no fato de que somente a estatização desses subsistemas permite controlar as condições da vida e de subsistências que estão fora do mercado e assegurar o controle sobre o trabalhador assalariado.

Esta pequena introdução é necessária para sairmos da tábula rasa do mito liberal -reconstruído pelos neos - de uma suposta "neutralidade”, "imparcialidade” do Estado. Do mesmo modo, o Estado não pode ser compreendido como um bloco monolítico, mas como o define Poulantzas, este possui uma autonomia relativa

... em relação a tal ou qual fração e componente desse bloco, em relação a tais ou quais interesses particulares. Autonomia constitutiva do Estado capitalista: remete à materialidade desse Estado em sua separação relativa das relações de produção, e à especificidade das classes e da luta de classes sob o capitalismo que essa separação implica. (POULANTZAS, 1985, p.146).

A burguesia, por sua vez, apresenta-se dividida em frações de classe (capital monopolista e não monopolista), fracionamentos que se desdobram na atual fase de internacionalização do capital, essa fração de classe compõe o bloco no poder. Nas palavras de Poulantzas (1985, p.146-147):

a) O Estado detém sempre uma autonomia relativa a essa ou aquela fração do bloco no poder, [...] a fim de assegurar a organização do interesse geral da burguesia sob a hegemonia de uma de suas frações $[\ldots .$.$] ;$

b) Tudo isso ainda é verdadeiro mesmo se as formas atuais do processo de monopolização e a hegemonia particular do processo de monopolização e a hegemonia particular do capital monopolista sobre o conjunto da burguesia impõem incontestavelmente uma restrição da autonomia do Estado em relação ao capital monopolista e do campo de compromissos deste com as outras frações da burguesia.

Pensar nas frações de classe, ou a classe no bloco do poder, significa, mesmo que brevemente, contemplar o papel do imperialismo, e os percalços na realização de políticas públicas com caráter universalizante, ganhos que podem ser computados ao brevíssimo período de Estado de Bem-Estar Social ${ }^{1}$, com políticas sociais como educação e saúde, etc

1 Sem querer entrar na polêmica se há ou não estado de bem-estar social nos países de capital dependente, o fato que os 30 anos de Estado de Bem-Estar Social pode ser computado plenamente na Europa. 
Lênin (2011), ao definir o imperialismo, afirma que este é a "fase superior do capitalismo". Nas palavras do autor:

O imperialismo é, pois, o capitalismo na fase de desenvolvimento em que ganhou corpo a dominação dos monopólios e do capital financeiro, adquiriu marcada importância a exportação de capitais, começou a partilha do mundo pelos trustes internacionais e terminou a partilha de toda a terra entre os países capitalistas mais importantes. (LÊNIN, 2011, p.218).

Uma das características desta fase do capitalismo é a partilha econômica do mundo e a ligação que se estabelece entre os grupos políticos e entre os Estados, relações “determinadas relações com base na partilha territorial do mundo, na luta pelas colônias, na 'luta pelo território econômico”" (LÊNIN, 201 1, p.218). De lá para cá muita água rolou neste moinho.

David Harvey (2013) e Ellen Wood (2014) classificaram este momento como "novo imperialismo". Para Harvey, o capitalismo global tem sofrido um crônico problema de superacumulação desde os anos 70. Superacumulação em um dado território implica um excedente de mão de obra (aumento do desemprego) e excedente de capital (que se manifesta num mercado abarrotado de bens de consumo que não podem ser vendidos sem perdas, como uma alta improdutividade e/ou como excedente de capital líquido carente de possibilidades de investimento produtivo). O novo imperialismo, como denomina Harvey, não necessita mais da ocupação territorial, é, neste sentido, um imperialismo de "desapossamento". Tese corroborada por Wood (2014, p.107-108). Para a autora, o novo imperialismo:

... diferentemente de outras formas de império colonial, depende mais que nunca de um sistema de múltiplos Estados nacionais mais ou menos soberanos. [...] O capital global exige muitos Estados-nação para executar as funções administrativas e coercitivas que sustentam o sistema de propriedade e oferecem o tipo de regularidade e previsibilidade diárias, bem como a ordem legal de que o capitalismo necessita mais que qualquer outra forma social. Nenhuma forma concebível de "governança global" poderia oferecer esse tipo de ordem diária ou as condições e acumulação que o capital exige.

O “Consenso de Washington”, na década de 1990 do século XX, demonstra essa mudança, na medida em que o poder imperial exigiu "ajustes estruturais" e "uma variedade de medidas que teriam o efeito de tornar essas economias ainda mais vulneráveis às pressões do capital global sob o comando dos Estados Unidos" (WOOD, 2014, p.103).

\section{O ESTADO DE BEM-ESTAR SOCIAL: UM BREVE INTERLÚDIO}

Não dá para falar do Estado de Bem-Estar Social sem mencionar os feitos da Revolução de Outubro, que este ano completa 100 anos. Segundo Hobsbawm (1995), o "breve século XX” não pode ser entendido sem a Revolução Russa e seus efeitos diretos e indiretos. Segundo o autor, ela salvaguardou o capitalismo liberal, possibilitando ao Ocidente ganhar a Segunda Guerra Mundial contra a Alemanha de Hitler e também fornecendo o incentivo para o capitalismo se reformar e abandonar a crença na ortodoxia do mercado. Esse curto período da história do capitalismo instaurou nos países centrais o chamado Estado de Bem-Estar Social. 
Draibe (2007, p.35) apresenta algumas características de um regime de bem-estar social. São eles:

a) Um dado padrão de provisão social, como o bem-estar é produzido e distribuído entre o Estado, o mercado e a família, e hoje, as ONGs;

b) Uma estrutura do sistema público de políticas sociais, composto pelos programas de previdência social, serviços de educação, saúde (mais ou menos universais), a assistência social e programas de transferências de renda a grupos sociais determinados (vulneráveis);

c) Um modelo dominante de solidariedade (individual ou universal), como e em que extensão o sistema de políticas sociais traduz, reforça ou reduz as desigualdades, os interesses e o poder na sociedade; etc.

Sem entrar na polêmica se, no Brasil, tivemos ou não um Estado de Bem-Estar Social, ou ao que Oliveira (1999) denominou de Estado de Mal-Estar, pois, diferentemente do processo de regulação pública, característica do Welfare State, vimos aqui, ao contrário, uma "privatização do público, sem uma publicização do privado” (OLIVEIRA, 1990, 67). Característica de um Estado autoritário que desenha os "perfis da mescla estatal-privado, eliminado o público, justamente pela ausência de uma esfera que, emanando do social, regularia politicamente os conflitos”.

Lautier (2012, p.140), ao discutir o difícil percurso para a universalização da proteção social na América Latina, destaca o enfoque para as políticas focalizadas (aos pobres, de forma geral). No Brasil, destaca-se, por exemplo, o Bolsa-Família². O caminho, diz o autor, “[ [... para um sistema de proteção social universalista implica que toda a população esteja dotada de direitos sociais universais e não de 'direitos sociais dos pobres”. A Constituição de 1988 foi um marco importante que pontua pequenos avanços no sentido de universalização de políticas sociais, como a proposta do SUS. Mas mal tendo tempo de se estabelecer as conquistas formuladas na Carta, dá-se início, nos anos 1990, ao desmanche do Estado, ou Reforma do Estado, iniciado no Governo FHC. Nessa Reforma, já que a globalização exige novas modalidades mais eficientes de administração pública, cresce a importância de uma forma nem privada nem estatal de executar os serviços sociais garantidos pelo Estado. Por isso, a necessidade de as organizações não estatais de serviço público operarem nas áreas de educação, saúde e cultura com “financiamento do Estado”. A reforma promoveria esse Estado fortalecido, com finanças recuperadas, a administração obedecendo a critérios gerenciais de eficiência, e o reforço das organizações não estatais produtoras de serviços sociais. Estas organizações contribuiriam, portanto, para uma mudança de perfil do Estado: de social-burocrático ou "Estado para um Estado social-liberal, que proteja os direitos sociais ao financiar as organizações públicas não-estatais”, essas sim eficientes porque introduzem a "competição e a flexibilidade na provisão desses serviços" (BRESSER PEREIRA; GRAU, 1999, p.16-17). As reformas propostas nos idos dos anos 1990, nos marcos estabelecidos pelas agências como FMI e Banco Mundial, coincidem, pelo menos no caso da América Latina, com o que parecia um desgaste das políticas neoliberais no continente e a ascensão de governos com caráter mais popular (Brasil, Bolívia, Paraguai, Equador).

O governo do PT, ao tomar posse em 2003, pareceu reascender as esperanças de uma parte da esquerda ligada aos movimentos populares e sindicais, embora em grande medida a sua

2 As políticas focais no Brasil vão se acomodando conforme o Governo. O Bolsa-Família implementado no Governo Petista (2003-2016) sofreu duras críticas à direita e à esquerda. Os primeiros, porque alimentaria a vagabundagem, a preguiça; os segundos pela ineficiência se não associada a política de inserção social como emprego. 
administração não fazia nenhum corte profundo com o governo anterior de FHC (1995-2002). Apesar disso, o governo Lula apresentou algumas novidades: conforme assinalado durante a campanha, duas frações do grande capital passaram a ter melhor assento no bloco no poder (MACHADO, 2008).

Boito Júnior (2006, p.238 ), ao analisar o governo Lula, considera que este alterou a relação do Estado brasileiro com a burguesia ao

... melhorar a posição da grande burguesia interna industrial e agrária no interior do bloco no poder. Essa mudança aparece principalmente na política de exportação, que tem propiciado saldos positivos crescentes na balança comercial do país. Note-se que se tratou de um deslocamento no interior do grande capital, com o grupo das pequenas e médias empresas permanecendo na mesma posição subordinada que já ocupava ao longo da década de 1990.

Os governos petistas viveram profundamente essa contradição. Ao apostar na "conciliação de classes” e, portanto, acreditar que o incentivo ao desenvolvimento de uma burguesia nacional, estava assegurado o projeto político de uma certa redistribuição: ampliação da educação, bolsa família, etc.

Coincide também com uma "cooptação" das organizações de classe: sindicatos, etc. As eleições de 2014 polarizaram dois projetos (que se encontram no final da linha). De um lado, as propostas do governo Dilma que prometia as garantias mínimas de direitos; de outro, o projeto do PSDB que de forma escancarada anunciava um aprofundamento da reforma do Estado, iniciada nos anos 1990.

Perdeu na urnas, tratou de ganhar na marra. O curioso é que embora esse projeto tenha sido derrotado, o governo do PT inicia sua implementação, digamos, em doses homeopáticas.

\section{CONCLUSÃO}

As propostas, hoje, colocadas pelo capital de retirar os direitos conquistados pelos trabalhadores, só podem ser compreendidas à luz dessa política. Ocorre em todo o mundo; no nosso caso, em particular significa a volta à barbárie. A Reforma Trabalhista deixa os trabalhadores sem nenhuma proteção; a reforma da Previdência condena o trabalhador a trabalhar até morrer.

Nenhum sistema legal é cego à dimensão de classe, embora como resultado da atividade política dos trabalhadores ao longo dos últimos dois séculos, a situação tenha de fato tendido, após 1945, a ficar um pouquinho melhor do que antes. É esta melhora na posição das classes trabalhadoras que a ideologia conservadora ressurge em todo o mundo desde os anos 1970 (WALLERSTEIN, 2002, p.100).

Para finalizar, o grande desafio hoje para as políticas públicas trata-se, neste momento, não de expansão dessas políticas, mas garantir o que as gerações anteriores conquistaram. Só é possível impedindo os avanços brutais da burguesia a esses direitos, tomando as ruas, apresentando alternativas ao desmonte do Estado.

O Estado, tanto nas economias imperiais quanto nas subordinadas, ainda oferece as condições indispensáveis de acumulação para o capital global, tanto como para as empresas locais e, em última análise, é o criador das condições que permitem ao capital global sobreviver e navegar 
102 - RBTS - v.4, n.2, 2017

o mundo [...], como diz Wood (2014). Então, sem ignorar as relações que transcendem o local, é necessário travar a luta no interior dos estados-nacionais. No caso dos trabalhadores buscando extrapolar essas fronteiras. Jacques Rancière (2014), num pequeno livro, O ódio à democracia, demonstra como as classes dominantes, quando lhe é necessário, abre mão dela sem nenhum pudor, sem ruborizar.

\section{REFERÊNCIAS}

BOITO JR., A. A burguesia no Governo Lula. In: BASUALDO, E. M.; ARCEO, E. Neoliberalismo y sectores dominantes. Tendencias globales y experiencias nacionales. Buenos Aires: CLACSO - Consejo, Latinoamericano de Ciencias Sociales, 2006.

DRAIBE, S. Estado de Bem-Estar, desenvolvimento econômico e cidadania: algumas lições da literatura econômica. In: HOCHMAN, G.; ARRETCHE, M.; MARQUES, E. (Org.). Políticas Públicas no Brasil. Rio de Janeiro: Fiocruz, 2007.

HARVEY, D. O novo imperialismo. São Paulo: Loyola, 2013.

LAUTIER, B. O difícil percurso para a universalização da proteção social na América Latina. In: COUTINHO, J. A.; LOPES, J. B. Crise do capital, lutas sociais e políticas públicas. São Paulo: Xamã, 2012.

LENNIN, V. I. O Imperialismo fase superior do capitalismo. Lisboa: Avante, 1975.

MACHADO, E. Governo Lula, neoliberalismo e lutas sociais. Lutas Sociais 21/22. São Paulo, 2008.

OLIVEIRA, F. À sombra do Manifesto Comunista: globalização e reforma do Estado na América Latina. In : SADER, E.; GENTILI, P. Pós-neoliberalismo II: Que Estado para que democracia?. Petrópolis: Vozes, 1999.

OLIVEIRA, F. A metamorfose da arribaçã: Fundo Público e regulação autoritária na expansão econômica do Nordeste. CEBRAP, Novos Estudos 27, 1990.

POUlantZaS, N. Poder Político e classes sociais. São Paulo: Martins Fontes, 1977.

POUlantZas, N. O Estado, o Poder, o Socialismo. 2. ed. Rio de Janeiro: Edições Graal,1985.

RANCIÈRE, J. O ódio à democracia. São Paulo: Boitempo, 2014.

SAES, D. A formação do Estado burguês no Brasil: 1885-1891. Rio de Janeiro: Paz e Terra, 1985.

WALLERSTEIN, I. O fim do mundo como o concebemos: ciência social para o século XXI. Rio de Janeiro: Revan, 2002.

WOOD, E. M. O Império do capital. São Paulo: Boitempo, 2014. 